\title{
Implementation of modular learning approach in relation to the performance of grade 5 pupils at Bagong Pag-asa Elementary School
}

\author{
Omnes, Agnes Q. $\triangle$ \\ Emilio Aguinaldo College, Philippines (agnes.omnes001@deped.gov.ph)
}

Received: 30 March 2021

Available Online: 8 July 2021
Revised: 15 May 2021 DOI: $10.5861 /$ ijrse.2021.662

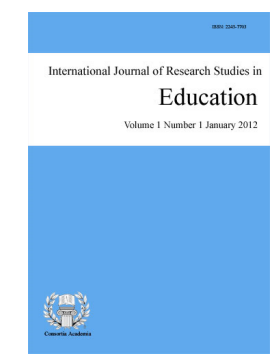

ISSN: 2243-7703 Online ISSN: 2243-7711

OPEN ACCESS

\section{Abstract}

The study respondents were the forty-five (45) Grade Five pupils who are enrolled in the modular learning modality of Bagong Pag - Asa Elementary School. The researcher used one group of respondents in the modular class. The researcher utilized non-probability sampling, specifically the purposive sampling technique, in determining the section that served as the respondents of the study. The study used a descriptive research method to determine the relationship between the extent of implementation of modular learning approach concerning the performance of Grade 5 pupils. More so, she utilized the researcher-modified instruments based on the International Module Evaluation Questionnaire. The study found out that the implementation of the Modular Approach is highly implemented with an overall mean of 3.78. Furthermore, the majority of the learners obtained a Very Satisfactory rating. There is a significant relationship between item 9, which states that the implementation of the modular approach has given the learners enough time to learn on their own and the level of performance. As revealed by their average grade in the first quarter, the obtained p-value of 0.00 does not exceed at 0.05 level of significance. Thus the null hypothesis is failed to reject. The result implies that the modular approach's implementation helped learners learn information that could lead them independently. Furthermore, due to many tasks, distractions, and lack of attention, the key difficulties and obstacles that the students have faced are self-studying, poor internet access, lack of sleep, and time to address all of the modules.

Keywords: modalities, face to face, online learning, Covid-19, module-ator, self-learning modules 


\section{Implementation of modular learning approach in relation to the performance of grade 5 pupils at Bagong Pag-asa Elementary School}

\section{Introduction}

Traditional education programs have been one of the first victims of the COVID-19 pandemic around the world. Face-to-face instruction has been phased out at several schools, colleges, and universities. The need for innovation and implementation of the alternative education system and assessment strategies has become urgent. The pandemic has provided us with an opportunity to pave the way for introducing different learning delivery modalities.

There is a paradigm shift in the way educators deliver quality education-through various modalities. Distance learning and continuing education have become a panacea for this unprecedented global pandemic, despite the challenges posed to both educators and learners. However, transitioning from traditional face-to-face Learning to distance learning can be an entirely different experience for the learners and the educators. They must adapt with little or no other alternatives available.

To ensure that Learning remains unhampered, the Department of Education (DepEd) has implemented distance learning modalities, various delivery modes where interaction occurs between the teacher and the students during instruction, who are geographically separated from one another. This suggests that lessons will be presented in a manner other than the conventional face-to-face format. The distance learning modalities, modular distance learning, or learning through printed and digital modules, have emerged as the most common among parents with children enrolled this academic year. This is also considering the learners in rural areas where the internet is not accessible for online Learning.

In several countries, modules are increasingly being used to organize language curricula. Consequently, many course books are now structured based on "modules" rather than "units." The term "module" is inextricably related to the notion of a flexible curriculum. The modular approach to teaching allows the learner to have more influence over his or her Learning and take greater responsibility for his or her education. It necessitates greater maturity on the part of the learner; however, the modules are more suitable for older students (French, 2015).

In the Philippines set-up, the teacher takes the responsibility of monitoring the progress of the learners. Learners can contact the instructor via e-mail, phone, text message/instant messaging, and other methods. If practicable, the teacher may make home visits to students that need remediation or assistance (Llego, n.d.). Printed Modules are being delivered to students, parents, or guardians by the teachers or through the Local Government Officials. Since education is no longer confined to the classroom, parents have become educators' partners. As home facilitators, parents play a critical role.

Their primary role in modular Learning is to establish a connection and guide the child. (FlipScience, 2020). According to the Department of Education (DepEd), parents and guardians perform the various roles in Module-ator, Bundy-clock, and the Home Innovator are all examples of modular Learning. As a Module-ator, they are in charge of collecting and submitting printed Self-Learning Modules (SLMs) from and to schools or barangay halls at the start and end of the week, depending on the parents' and school's agreement. They have to review their child's timetable or workweek plan as a Bundy-clock. Lastly, as Home Innovators, they must provide their child with a productive learning environment to help them focus more on Learning. It must be a well-lighted and well-ventilated space in the house, with little or no distraction. The use of modules facilitates self-directed Learning.

One of the benefits of using modules for instruction is acquiring better self-study or learning skills among students. Students actively participate in understanding the concepts discussed in the module. They gain a sense 
of responsibility when they complete the tasks in the module. With little or no assistance from others, the learners progress on their own. They are learning how to learn; they are empowered (Nardo, M.T.B, 2017). Other benefits of modular teaching include improved adaptability of instructional resources, more choice and self-pacing for students, more variety and flexibility for teachers and staff, and more variety and flexibility for teachers and staff.

Considering the views on the implementation of modular distance learning, it would be important to determine how learners cope up and perform under it. Currently, modular Learning emphasizes the utilization of student-centered pedagogies and continuous assessment methods through Active Learning. Therefore, as an elementary teacher, the researcher would like to delve into implementing a modular learning approach concerning the performance of Grade 5 at Bagong Pag-Asa Elementary School.

According to Dangle (2020), the face-to-face learning engagement of students and teachers has been suspended due to the COVID-19 pandemic. As a result of the pandemic, Modular Distance Learning has been implemented as an immediate response to ensure educational continuity. The Philippines is currently transitioning to a new normal type of education, and educators' constant advances and active participation from other stakeholders are the driving forces behind its progress. The main goal of this study is to learn about the challenges, thoughts, and suggestions of teachers, parents, and students involved in the implementation of Modular Distance Learning in Balbalayang National High School (BNHS) and Baguio City National High School (BCNHS) in the School Year 2020-2021. The 37 participants in the selected schools were surveyed using a mixed quantitative and qualitative methodology, with quota and purposive sampling used to identify these problems, views, and recommendations. The main challenges that emerged were lack of school funding in the production and delivery of modules, students struggling with self-studying, and parents' lack of knowledge to academically guide their child/children. Finally, the study was able to identify the participants' current resources, preparedness, and communication difficulties. The findings of this study could be used to develop current school programs and include guidance for implementing modular distance learning.

Bernardo (2020) added that Learning by printed and interactive modules emerged as the most favored distance learning tool for parents who enrolled their children in the coming school year, based on a survey conducted by the Education Department (DepEd). (DepEd). Parents and guardians are requested to address DepEd's Learner Registration and Survey Form over the 45-day enrollment period in public schools ending July 15. They were asked about their favorite alternative learning style and tried to profile the enrollee's preparation for distance learning. The DepEd survey findings found that 8.9 million parents favored modular distance learning, where home students would study by self-learning modules.

Similarly, Codamon (2020) claimed that for the Written Modular Learning Delivery Modality, teachers prepare to learn materials, weekly research guides, and other tools for modular distance learning. These materials are supplemented by quality assured instructional kits in which parents/guardians or para-teachers communicate with teachers and receive guidance and instructions. Parents use the learning plan to oversee their child's contact with the content and collaborate with the teacher. They do module exercises with the other students, complete the individual learning screen, communicate with the instructor for input by email, messenger, or any means of communication.

In planning for the school year 2020-2021, the Department of Education (DepEd) provided self-learning modules (SLMs) with alternate learning delivery modalities for different categories of learners around the Philippines. Integrating SLMs with alternate learning delivery modalities (modular, television-based, radio-based teaching, mixed, and online) would allow DepEd to ensure that all learners have access to high-quality basic education for SY 2020-2021 with face-to-face classes already barred due to public health.

DepEd issued a series of contextualization SLMs for each area to be printed in July and prepared for national distribution, including coastal and far-flung learners. The Department has ensured that teachers' and staff's welfare and wellbeing will be their greatest concern, as SLMs can be completed in the comfort of their 
Omnes, A. Q.

home. Teachers who need to visit their schools to plan the SLMs need to follow the current job arrangements and health protocols. To further align SLMs with learning delivery modalities, DepEd will finalize the learning delivery modalities to be adopted for each area following the convergence of Learner Enrollment and Survey Forms (LESF) from June enrollment (DepEd, 2020).

Further, Ambayon (2020) said that the developed module consisted of excellent contents, relevance, and mechanics as evaluated by experts in the area. Students rated the module as extremely appropriate, valid, dependable, and functional. Control and experimental groups were formed among the students. The groupings were based on their GPA during the previous semester. The experimental group used the created module but not the control group. The test instruments were the various activities given after each subject and lasted one hour each session. According to the findings, the experimental group's performance in literature increased from mediocre to outstanding, while the control group's performance improved only slightly. As a result, the module is recommended for use in similar contexts, particularly when studying mythology and folklore.

\subsection{Significance of the study}

The following individuals benefited from this study:

Schools Division Office/ Curriculum Planners. They may enhance the existing SLMs by using the feedback gathered. Also, it may help to revisit policies and guidelines that may enhance the performance level of learners and implementation of the modular approach.

School Heads. They may call for effective implementation and identify weak areas that provide a basis to reinforce existing programs, projects, and activities about the modular approach.

Teachers. They may be able to get reinforcements in terms of enhancing the performance level of learners. Also, this may help alleviate problems they encountered in implementing the modular approach.

Parents. They may realize the importance of the role they play involving themselves in the Learning and development of their child.

Pupils. They may get more information on how they can maximize the modular approach for their benefit.

Researchers. They may pursue hybrid studies in line with modular approach modality and enhancing performance levels among pupils. Further, this study may be a basis for scholarly work about the subject.

\section{Research methodology}

This chapter presents the subject of the study or the participants, data gathering methods, and data analysis plan.

\subsection{Sampling}

The study respondents were the forty-five (45) Grade Five pupils who are enrolled in the modular learning modality of Bagong Pag - Asa Elementary School. The researcher used one group of respondents in the modular class. The researcher utilized non-probability sampling, specifically the purposive sampling technique, to determine the section that served as the study's respondents.

\subsection{Data collection}

The study used a descriptive research method to determine the relationship between the extent of implementation of modular learning approach concerning the performance of Grade 5 pupils. More so, she utilized the researcher-modified instruments based on the International Module Evaluation Questionnaire. 
The data for this research were collected from instrument used. The following range of scores to be used and the corresponding verbal interpretations on the extent of implementation of modular learning approach are as follows:

\begin{tabular}{cc}
\hline Score & Verbal Interpretation \\
\hline 4 & Highly Implemented (HI) \\
3 & Implemented (I) \\
2 & Moderately Implemented (MI) \\
1 & Less Implemented (LI) \\
\hline
\end{tabular}

In addition to the researcher-made questionnaire, the registration method was used to collect data about the academic grades of the pupils as revealed by the average grade in the first quarter. These data were collected from the adviser of the pupils. To interpret the performance of pupils as revealed by their average grade in the first quarter, the following ranges and interpretations were utilized:

\begin{tabular}{cc}
\hline Grading Scale & Verbal Interpretation \\
\hline $90-100$ & Outstanding \\
$85-89$ & Very Satisfactory \\
$80-84$ & Satisfactory \\
$75-79$ & Fairly Satisfactory \\
Below 75 & Did Not Meet Expectations \\
\hline
\end{tabular}

The survey questionnaire used in the study was submitted to the adviser to gather initial comments and suggestions to improve the questionnaire checklist. After the revision of the instrument, experts with a reasonable background in test construction validated the questionnaire checklist and on the topic to comment on its content to finalize the items to be included in the instrument. Upon completion of the content validation form, the researchers sought permission from the principal's office to administer the instrument to the respondents. Then, immediate retrieval of the instrument was done.

\subsection{Data analysis}

To determine the extent of implementation of the modular approach assessed by the respondents, mean was utilized. To determine the level of performance of grade 5 pupils as revealed by their average grade in the first quarter, frequency and percentage distribution were applied. To determine if there is a significant relationship between implementing the modular approach and the level of performance of grade 5 pupils as revealed by their average grade in the first quarter, Pearson ' $r$ ' correlation was utilized. A qualitative approach was utilized to find out the problems encountered in the implementation of the modular approach. In addition, the results gathered from the instrument and the performance of the pupils were treated and interpreted using the appropriate statistical tools mentioned above.

\section{Findings and discussion}

This study aimed to determine the relationship between the extent of implementation of modular learning approach concerning the performance of Grade 5 pupils at Bagong Pag-Asa Elementary School during the school year $2020-2021$.

\subsection{What is the extent of implementation of the modular approach assessed by the respondents?}

It can be gleaned from the table that the overall mean of implementing the modular approach is 3.78 verbally interpreted as Highly Implemented. It means that the implementation of the modular approach has learning activities and materials that were useful and helpful in making their performance task. It can also imply that the modular approach enabled learners to answer the module correctly and return it on time. The findings suggest that the teacher may provide learning activities that could develop independence among grade 5 learners. 
Omnes, A. Q.

\section{Table 1}

The extent of implementation of the modular approach assessed by the respondents

\begin{tabular}{|c|c|c|}
\hline $\begin{array}{l}\text { The extent of Implementation of Modular Approach } \\
\text { The implementation of the modular approach has... }\end{array}$ & Mean & Verbal Interpretation \\
\hline $\begin{array}{l}\text { provided me with timely and helpful information and guidance at } \\
\text { the start of the module. }\end{array}$ & 3.76 & Highly Implemented \\
\hline learning activities that have helped me to learn. & 3.78 & Highly Implemented \\
\hline learning materials provided were helpful to me & 3.87 & Highly Implemented \\
\hline given me independence for Learning & 3.60 & Highly Implemented \\
\hline $\begin{array}{l}\text { provided me with timely and helpful information and guidance on } \\
\text { the assessment requirements and criteria }\end{array}$ & 3.78 & Highly Implemented \\
\hline provided me guidance from my teachers to support my studies & 3.80 & Highly Implemented \\
\hline provided electronic learning resources were appropriate & 3.80 & Highly Implemented \\
\hline helped to develop my skills and qualities & 3.80 & Highly Implemented \\
\hline given me enough time to learn at my own pace & 3.73 & Highly Implemented \\
\hline $\begin{array}{l}\text { enabled me to get and return the printed module copies to the } \\
\text { school }\end{array}$ & 3.91 & Highly Implemented \\
\hline Overall & 3.78 & Highly Implemented \\
\hline
\end{tabular}

3.2 What is the level of performance of grade 5 pupils as revealed by their average grade in the first quarter?

\section{Table 2}

Level of performance of grade five pupils as revealed by their average grade in first quarter

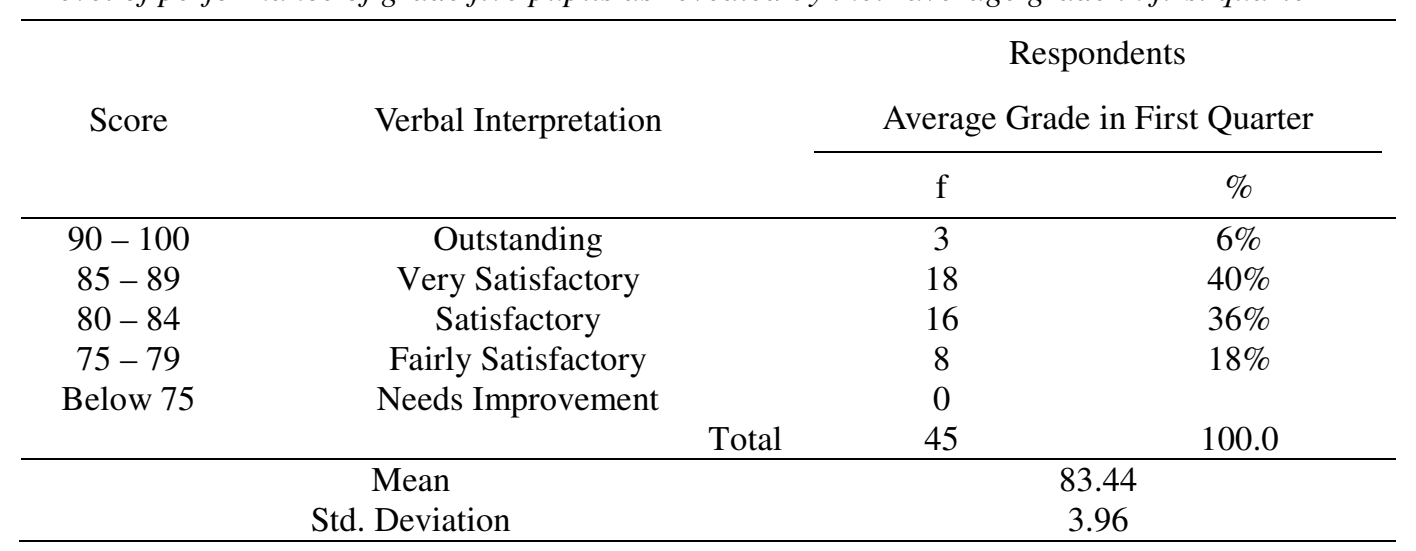

It can be gleaned from the table that most learners obtained a Very Satisfactory rating, followed by sixteen learners who have a satisfactory rating, and eight learners got a fairly satisfactory rating. Meanwhile, three of them garnered an outstanding rating. It implies that learners performed well in their first quarter. The findings suggest that the few learners who got fairly satisfactory ratings should focus more on their weaknesses, and they should study their lesson well to have a good grade in the next quarter.

\subsection{Is there a significant relationship between the extent of implementing the modular approach and the level of}

performance of grade 5 pupils as revealed by their average grade in the first quarter?

The table reveals that it was statistically found out that there is a significant relationship between item 9, which states that the implementation of the modular approach has given the learners enough time to learn on their own. The level of performance as revealed by their average grade in the first quarter since the obtained $p$-value of 0.00 does not exceed at 0.05 level of significance. Thus the null hypothesis is failed to reject. It simply shows that the implemented modular approach impacted the achievement of learners in the new normal. The result implies that the modular approach's implementation helped learners learn information that could lead them independently. However, the nine (9) items show no significant relationship on the level of performance since the obtained $p$-value of 0.00 exceeds at 0.05 level of significance. Thus the null hypothesis is rejected. It

62 Consortia Academia Publishing (A partner of Network of Professional Researchers and Educators) 
Implementation of modular learning approach in relation to the performance of grade 5 pupils simply means that the modular approach did not significantly correlate to the learners' performance in the new normal.

\section{Table 3}

Relationship between modular approach and the level of performance of grade 5 pupils

\begin{tabular}{cccccc}
\hline $\begin{array}{c}\text { The extent of } \\
\text { Implementing the } \\
\text { Modular Approach }\end{array}$ & $\begin{array}{c}\text { Level of } \\
\text { Performance }\end{array}$ & Computed r & Sig & Decision on Ho & Interpretation \\
\hline Item 1 & & .157 & .303 & Rejected & Not Significant \\
Item 2 & -.035 & .820 & Rejected & Not Significant \\
Item 3 & .061 & .690 & Rejected & Not Significant \\
Item 4 & Average & -.116 & .449 & Rejected & Not Significant \\
Item 5 & Grade (First & -.062 & .685 & Rejected & Not Significant \\
Item 6 & Quarter) & .057 & .711 & Rejected & Not Significant \\
Item 7 & & .229 & .130 & Rejected & Not Significant \\
Item 8 & & .170 & .264 & Rejected & Not Significant \\
Item 9 & & .299 & .046 & Failed to Reject & Significant \\
Item 10 & & .104 & .496 & Rejected & Not Significant \\
\hline
\end{tabular}

\section{Conclusion}

Based on the analysis and interpretation of the data, the following findings are summarized: The implementation of the Modular Approach is highly implemented with an overall mean of 3.78. Furthermore, the majority of the learners obtained a Very Satisfactory rating. There is a significant relationship between item 9, which states that the implementation of the modular approach has given the learners enough time to learn on their own. The level of performance as revealed by their average grade in the first quarter since the obtained p-value of 0.00 does not exceed at 0.05 level of significance. Thus the null hypothesis is failed to reject. The result implies that the modular approach's implementation helped learners learn information that could lead them independently. Self-studying, weak internet access, lack of sleep, and time to address all of the modules due to many tasks, distractions, and lack of attention are the key issues and obstacles students face.

\section{References}

Ambayon, C. M. (2020). Modular-based approach and students' achievement in literature. International Journal of Education \& Literacy Studies, 8(3). https://doi.org/10.7575/aiac.ijels.v.8n.3p.32

Bernardo, J. (2020). Module delivery, parents answering activity sheets: Challenges seen in distance learning simulations. Retrieved from https://news.abscbn.com/news/08/31/20/module-delivery-parents-answering-activity-sheets-challengesseen-in-distance-learning-simulations

Codamon, D. (2020). Understanding the distance learning delivery modalities. Retrieved from https://pia.gov.ph/news/articles/1049277

Dangle, Y. R. P. (2020). The implementation of modular distance learning in the Philippine secondary public schools. International Conference on Advanced Research in Teaching and Education, 3(2).

DepEd. (2020). DepEd prepares self-learning modules for education's new normal. Retrieved from https://www.deped.gov.ph/2020/07/02/deped-prepares-self-learning-modules-for-educations-new-norm al/

French, S. (2015). The benefits and challenges of modular higher education. Retrieved from https://melbournecshe.unimelb.edu.au/_data/assets/pdf_file/0006/2774391/Benefits_Challenges_Modu lar_Higher_Ed_Curricula_SFrench_v3-green-2.pdf 
Omnes, A. Q.

64 Consortia Academia Publishing (A partner of Network of Professional Researchers and Educators) 